\title{
B cell clonality in gastric lymphoid tissues of patients with Sjögren's syndrome†
}

\author{
Gianfranco F Ferraccioli, Dario Sorrentino, Salvatore De Vita, Lucia Casatta, \\ Antonella Labombarda, Claudio Avellini, Riccardo Dolcetti, Dario Di Luca, \\ Carlo Alberto Beltrami, Mauro Boiocchi, Ettore Bartoli
}

Department of

Internal Medicine,

School of Medicine,

Udine, Italy

G F Ferraccioli

L Casatta

D Sorrentino

E Bartoli

A Labombarda

Department of

Pathology

C Avellini

C A Beltrami

$1^{\circ}$ Division of

Experimental

Oncology,

Centro Riferimento

Oncologico, Aviano,

Pordenone

$S$ DeVita

R Dolcetti

M Boiocchi

Institute of

Microbiology,

School of Medicine, Ferrara, Italy

D Di Luca

Correspondence to:

Dr G F Ferraccioli,

Rheumatic Disease Unit,

Department of Internal

Medicine, School of

Medicine, Udine, Italy.

†Presented in abstract form at the 58th ACR Meeting, Minneapolis, 22-26 October, 1994.

Accepted for publication 16 January 1996

\begin{abstract}
Objective-To determine the prevalence of mucosa associated lymphoid tissue (MALT) in the stomach and of a possible antigen driven proliferation, in patients with Sjögren's syndrome (SS).

Methods-Twenty one patients with primary SS and 80 dyspeptic controls underwent upper endoscopy. Lymphoid tissue and Helicobacter pylori were assessed by histopathological analysis. Epstein-Barr virus (EBV) or human herpes virus-6 (HHV-6) genome were studied by polymerase chain reaction (PCR) DNA amplification. Two PCR VDJ procedures were used to detect immunoglobulin heavy chain (IgH) gene rearrangement.

Results-Organised MALT was found in $33.3 \%$ of the patients, compared with $21.5 \%$ of the controls (NS). H pylori infection was seen in $71 \%$ of patients and $63 \%$ of controls. Genomic EBV or HHV -6 was found in a minor portion of SS gastric tissues. B cell expansion was detected in nine of the 21 patients. Infectious agents in the stomach might have contributed to $B$ cell clonality only in $55.5 \%$ of the cases. No strict relationship was found between lymphoid follicles and clonality.

Conclusion-Lymphoid accumulation in the gastric mucosa is common in Sjögren's syndrome, but full evidence for an antigen driven $B$ cell expansion could not be demonstrated. Only a portion of those with clonal B cell expansion had evidence of an infectious agent. Other unknown infectious agents or factors related to the underlying disease (autoantigen) and its tissue environment may have a further role as possible causes of $B$ clonal expansion in the gastric mucosa.
\end{abstract}

(Ann Rheum Dis 1996; 55: 311-316)

Isaacson's group originated the concept of lymphoproliferative diseases of the mucosa associated lymphoid tissue (MALT), ${ }^{1}$ describing the expansion of migrated lymphoid cells to the gastric mucosa, which normally does not contain organised lymphocytes. ${ }^{1}$ It has recently been proposed that, in the presence of a persistent antigenic stimulus, MALT may proliferate and even transform into a full blown lymphoma. ${ }^{2}$

Sjögren's syndrome (SS) is a disease characterised by lymphoid infiltration of the salivary glands, and frequent involvement of the gastrointestinal tract. Several agents have been considered as possible chronic stimuli (for example Epstein-Barr Virus (EBV), retroviruses, human herpes virus-6 (HHV-6)), and it may be that different agents are involved in different tissues. ${ }^{3-5}$

In the stomach, Helicobacter pylori has been claimed to be the main agent responsible for the appearance of lymphoid infiltrates. ${ }^{6}$ As SS may in itself represent a likely cause of lymphoid tissue migration to the mucosa of the gastrointestinal tract, ${ }^{8}$ we thought it would be of interest to study the gastric tissue in SS and define whether the presence of MALT in the stomach is a common occurrence in SS (patients with SS often report unspecific dyspeptic symptoms, attributed to a coexistent 'chronic gastritis', ${ }^{9}$ whether the presence of MALT in the stomach is associated with infectious agents such as $H$ pylori or viruses implicated in the pathogenesis of SS, ${ }^{3-5}$ and whether gastric MALT shows evidence of lymphoid proliferation and B cell clonal expansion possibly related to local chronic antigenic stimulation. ${ }^{10}{ }^{11}$

\section{Patients and methods}

Twenty one consecutive patients (median age 52 (range 30-70) years) among 50 with a diagnosis of primary SS according to the recently proposed criteria ${ }^{12}$ gave their consent to enter the study. The diagnostic criteria have yet to be fully validated, but may be considered at least as suitable as any others available in the literature. The patients were studied on an outpatient basis at the Rheumatic Disease Unit of the Department of Internal Medicine. All 21 had undergone salivary gland biopsy as part of the diagnostic procedure and 16 of them were of grade 3-4 according to Chisholm and Mason; ${ }^{13}$ the others had lower grading, but fully satisfied the criteria of sicca syndrome (xerostomia, salivary gland hypofunction, keratoconjunctivitis sicca, positive autoantibodies).

None of the patients had been taking xerogenic drugs, steroids, antibiotics or non-steroidal anti-inflammatory drugs in the previous three months. In the past, seven of these patients had taken brief courses of amoxicillin/ampicillin because of parotid infections, and 15 had taken low doses of steroids (prednisone $5-7.5 \mathrm{mg} /$ day) for short periods of time (two to eight weeks) because of arthralgia, arthritis, intercurrent swelling of their glands without infection, or other extraglandular manifestations. 
The study included a full clinical and immunological investigation: salivary gland and lachrymal function were tested, antinuclear antibodies (ANA), extractable nuclear antigen (ENA) and rheumatoid factor (RF) were measured, and HLA locus I and II typing was performed.

The gastritis was diagnosed histopathologically and its relationship with local infectious agents investigated. Evidence of B cell clonal expansion was sought in sera using a sensitive immunofixation technique able to demonstrate a monoclonal gammopathy, and tissue clonal B cell expansion was tested by genotypic analysis of the gastric tissue. The behaviour of the possible B cell clonal expansion and its relationship with $H$ pylori infection over time after treatment was investigated.

A control group of 80 patients, referred to us because of simple dyspepsia, but without any clinical sign of overt immunological diseases, underwent upper endoscopy with gastric biopsying.

\section{HISTOPATHOLOGY}

Upper endoscopy was performed using standard Olympus video instruments. Routinely, an average of five or six biopsy specimens were obtained from the antrum for histology, another was obtained for rapid urease test (CLO from Delta West, Bentley, Australia), and three more were taken for molecular studies; they were immediately frozen in liquid nitrogen and stored at $-70^{\circ} \mathrm{C}$. Virtually all the specimens included the muscularis mucosa. Samples from each specimen were mounted on slides and stained with haematoxylin-eosin and with a modified Giemsa stain to study the degree of inflammation and the presence of lymphoid follicles and $H$ pylori. The lymphoid component was graded on a scale of 0 (scattered plasma cells in lamina propria without lymphoid follicles) to 5 (diffuse infiltration-prominent lymphoepithelial lesions) (figure) according to the system proposed by Wotherspoon et al. ${ }^{14} \mathrm{~A}$ lymphoid follicle was defined as such when an unequivocal germinal centre was seen. Immunophenotype data of the lymphoid population were collected for B (CD20-L26-DAKO), T (CD3-T cell-DAKO), and $\kappa / \lambda$ chain (DAKO) restriction. Each set of biopsy specimens was examined by two pathologists ( $\mathrm{CAB}$ and $\mathrm{CA}$ ) blinded as to the clinical diagnosis and treatment, and the final grading represents the average of the two individual scores, the agreement being more than $90 \%$. Patients were classified as $H$ pylori positive or negative on the basis of both histology and the urease CLO test. When the two tests did not agree (two cases), classification was based on histology.

\section{GENOTYPIC ANALYSIS}

DNA was extracted from fresh frozen gastric specimens using standard procedures, and subjected to molecular studies after positive $\beta$ globin gene amplification. ${ }^{15}{ }^{16}$ Amplification of the IgH gene was performed in triplicate using two different seminested polymerase chain reaction (PCR) procedures, as described previously. ${ }^{11}$ Briefly, the upstream consensus primer was complementary to the third framework $\mathrm{V}$ region of the $\mathrm{IgH}$ gene in the first procedure ( $\mathrm{Fr} 3)$, and to the second framework $\mathrm{V}$ region in the second procedure $(\mathrm{Fr} 2)$. The downstream primers were the same in both the procedures, and were complementary to an outer conserved sequence of the $\mathrm{J}$ region in the first round of amplification, and to an inner conserved J region in the second round. The PCR product was run and evaluated optically on ethidium bromide stained agarose gel. B cell clonality was disclosed by one or more dominant bands within the predicted size range, and a smear without dominant bands within the predicted size range was taken as evidence of polyclonality. Positive and negative controls (B cell chronic leukaemia, reactive lymphnode, or no DNA) were routinely analysed and compared with the test samples. ${ }^{11}$ Further molecular analysis by radioactive VDJ PCR run on polyacrylamide gel and by DNA sequencing of the PCR product confirmed the validity of the procedure (manuscript in preparation).

EBV and HHV-6 sequences were sought by PCR techniques of comparable sensitivity, as described previously. ${ }^{15}$ Particular care was taken to avoid carryover artefacts, and this was obtained by analysing for EBV and HHV-6 in different laboratories (Aviano and Ferrara, respectively). Briefly, the presence of the EBV genome in tissue samples was investigated by amplification (35 rounds) of the EBV IR3 region, followed by Southern blot hybridisation of the PCR product by an internal ${ }^{32}$ P-labelled IR3 specific oligoprobe. HHV-6 was sought using the sets of primers described by Aubin et al $^{17}$ and specific ${ }^{32} \mathrm{P}$-labelled oligoprobe hybridisation of the PCR product. ${ }^{15}$ To increase sensitivity, the samples were also analysed by nested PCR, amplifying a $659 \mathrm{bp}$ fragment internal to the first round $832 \mathrm{bp}$ product.

\section{STATISTICAL ANALYSIS}

The $\chi^{2}$ exact test was used to determine differences for prevalence values between groups.

\section{Results}

Our patient population with primary SS had classical clinical, immunological, and histopathological findings: sialometry $<1.5 \mathrm{ml} / 15$ min; Shirmer test $<5 \mathrm{~mm} / 5 \mathrm{~min}$; focal sialoadenitis (grade 3-4) in the majority of the patients; $60 \%$ were DR3 positive; all were ANA $(60 \%)$ or RF $(60 \%)$ positive, or both. Ro antibodies were found in $42 \%$ and $\mathrm{La}$ antibodies in $21 \%$. Five patients had low serum levels of monoclonal gammopathy. Table 1 summarises the overall results of the analysis of infectious agents in the tissues and the related B cell clonal expansion.

MALT TISSUE IN THE STOMACH

We chose grade 2 (see figure) as the reference grading for MALT because it is histologically 

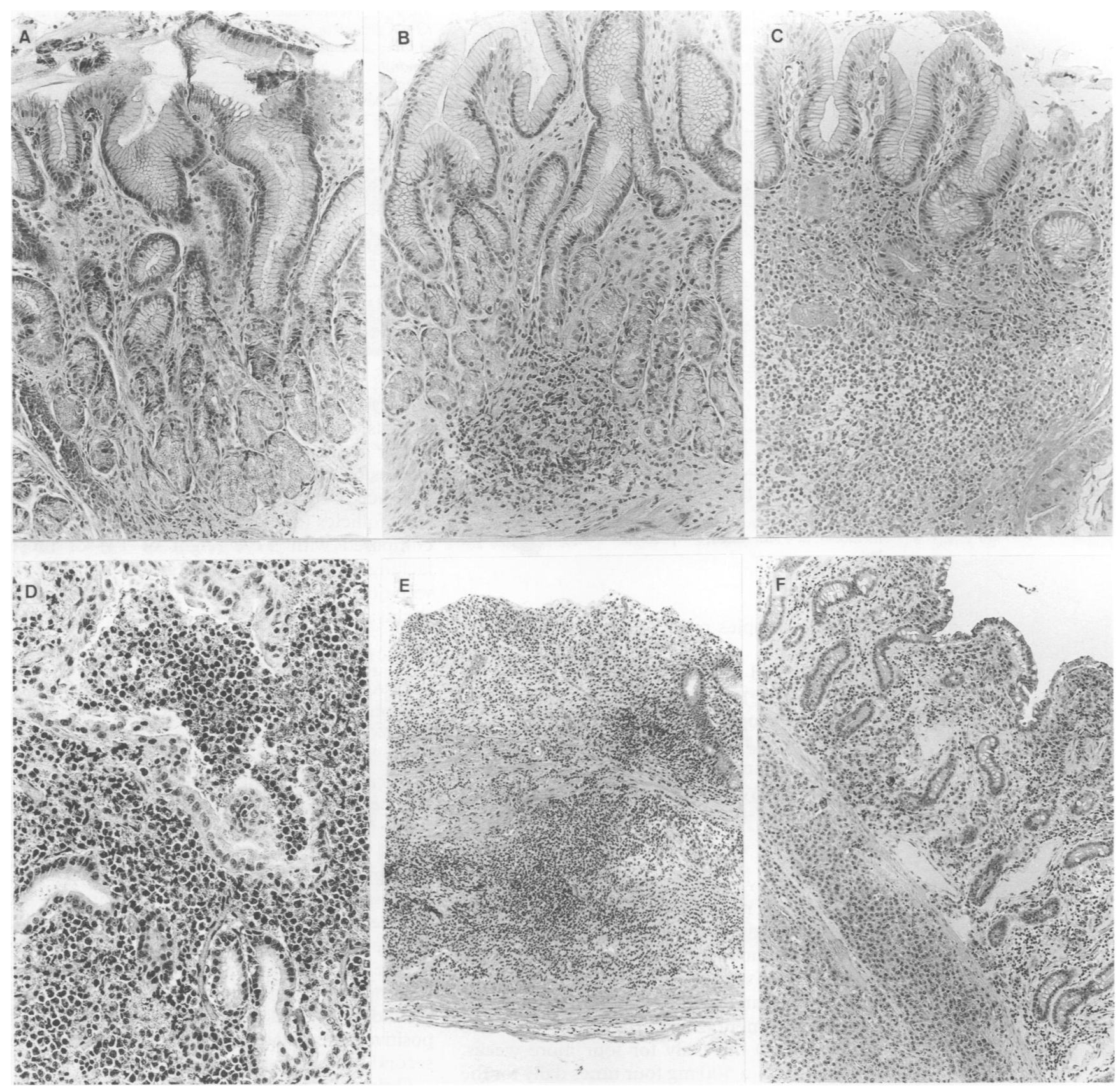

Gastric tissue lymphoid infiltrate according to Wotherspoon-Isaacson grading (WIG) score. A: Grade $0=$ scattered plasma cells in lamina propria; no lymphoid follicles. B: Grade 1 = small clusters of lymphocytes in lamina propria; no lymphoid follicles; no lymphoepithelial lesions. C: Grade 2=prominent lymphoid follicles with surrounding mantle zone and plasma cells; no lymphoepithelial lesions. D: Grade $3=$ lymphoid follicles surrounded by small lymphocytes that infiltrate diffusely in lamina propria and occasionally into epithelium. E: Grade $4=$ lymphoid follicles surrounded by centrocyte like cells that infiltrate diffusely in lamina propria (suspicious lymphoid infiltrate probably lymphoma). F: Grade $5=$ diffuse infiltration by centrocyte like cells; prominent lymphoepithelial lesions (lymphoma).

better defined than grade 1 and more easily recognised as a screening diagnosis. An organised (grade 2 or more) lymphoid tissue (MALT) as defined by Wotherspoon et al, ${ }^{14}$ was found in $33.3 \%$ of patients with SS, and in $21.5 \%$ (17 of 80 ) of disease control subjects (table 2); the difference between the two prevalences is not significant. A grade 3 or 4 tissue was observed in $14.3 \%$ of these patients with SS. Immunohistochemistry data revealed a lymphoid component comprised of T lymphocytes in the subepithelial region, associated with the usual B phenotype in the germinal centre and in the epithelium infiltrating lymphocytes. More detailed results of the histopathological study will be reported elsewhere. $H$ pylori infection was detected in 15 of 21 samples $(71 \%)$, in five of seven $(71 \%)$ of those with lymphoid follicles, but also in 10 of 14 $(71 \%)$ of those without follicles.

EBV genome was detected in two of the 21 SS samples $(9.5 \%)$ and, more specifically, in two of the seven samples with lymphoid follicles, but in none of those lacking them. In contrast, HHV- 6 was found in three of the 21 SS samples $(14.5 \%$ ) - two of seven with, and one of four without lymphoid follicles. Interestingly, only one of the three patients giving HHV-6 positive samples had the genome in blood cells.

\section{CLONAL ANALYSIS}

No evidence of $\kappa \lambda$ light chain restriction was found by immunohistochemistry in any patient. Clonality was found in nine $(42 \cdot 8 \%)$ 
Table 1 Helicobacter pylori infection and virological genotypic characteristics of gastric tissues in samples from patients with primary Sjögren's syndrome (VDF clonalities reported according to Fr2 or Fr3 procedure positivity)

\begin{tabular}{|c|c|c|c|c|}
\hline $\begin{array}{l}\text { Patient } \\
\text { No }\end{array}$ & $H P$ & $E B V$ & $H H V-6$ & $\begin{array}{l}\text { Clonality by } \\
V D\} P C R\end{array}$ \\
\hline 1 & - & + & - & - \\
\hline 2 & + & - & - & + \\
\hline 3 & + & - & - & + \\
\hline 4 & - & nt & - & + \\
\hline 5 & + & - & - & - \\
\hline 6 & - & - & - & + \\
\hline 7 & + & - & - & - \\
\hline 8 & + & - & - & - \\
\hline 9 & + & - & - & - \\
\hline 10 & + & + & - & - \\
\hline 11 & + & - & + & - \\
\hline 12 & - & - & + & + \\
\hline 13 & - & - & - & + \\
\hline 14 & + & - & + & - \\
\hline 15 & + & nt & - & - \\
\hline 16 & - & - & - & + \\
\hline 17 & + & - & - & - \\
\hline 18 & - & - & - & + \\
\hline 19 & + & - & - & - \\
\hline 20 & + & - & - & + \\
\hline 21 & + & - & - & - \\
\hline
\end{tabular}

$\mathrm{HP}=$ Helicobacter pylori $\quad \mathrm{EBV}=$ Epstein-Barr virus; HHV $6=$ human herpes virus 6 ; VDJ $=$ Clonal rearrangement detected through the $\mathrm{Fr} 2$ and $\mathrm{Fr} 3$ procedures (see materials and methods) $. \mathrm{nt}=$ Not tested; $+=$ positive, $-=$ negative response to test.

of the 21 samples processed by VDJ PCR (in five, by $\mathrm{Fr} 2$ and $\mathrm{Fr} 3$ procedures simultaneously, and in four by either the Fr2 or the Fr3 procedure). The five patients with monoclonal gammopathies in their sera were all positive for VDJ clonality in the stomach.

Among the nine SS tissues with evidence of B cell clonality, four samples had $H$ pylori, and one had HHV-6.

\section{SECOND BIOPSY}

Four patients negative for $H$ pylori underwent a second endoscopy with gastric biopsying at least three months after the previous one, together with six patients positive for $H$ pylori who were treated with a standard eradication treatment (omeprazole $40 \mathrm{mg}$ daily for two weeks and $20 \mathrm{mg}$ daily for four more weeks, with amoxicillin $500 \mathrm{mg}$ four times daily for the first two weeks). At the control assessment, one more, initially apparently negative, patient had become positive for $H$ pylori while, of six treated, three were negative on the second biopsy. Thus after the second biopsy, of 10 patients tested, four were $H$ pylori positive, compared with the six initially positive. All those cleared of $H$ pylori had a decrease in their Wotherspoon-Isaacson grading score. The number of samples showing an increased score for lymphoid infiltration had increased from two to three (table 3).

Table 2 Lymphoid follicles (LF) and Helicobater pylori (HP) infection in patients with Sjögren's syndrome and dyspeptic controls

\begin{tabular}{lcl}
\hline Patients & $L F(+)$ & $H P(+)$ \\
\hline $\begin{array}{l}\text { Siögren's } \\
(\mathrm{n}=21)\end{array}$ & $7(33 \cdot 3 \%)$ & $15(71 \%)$ \\
$\begin{array}{c}\text { Controls } \\
(\mathrm{n}=80)\end{array}$ & $17(21 \cdot 5 \%)$ & $50(63 \%)$ \\
$\chi_{\mathrm{c}}^{2}$ & $1 \cdot 29 \dagger$ & $0 \cdot 10 \dagger$ \\
\hline
\end{tabular}

$\dagger$ Not significant $\left(\chi_{c}{ }^{2}\right.$ non-parametric test, comparing \% values for patients and controls).
Table 3 Helicobacter pylori (HP) and VDf analysis in tissues graded according to the Wotherspoon-Isaacson grading score: follow up data in patients with Sjögren's syndrome

\begin{tabular}{lllllll}
\hline Patient No & $H P-1$ & $H P-2$ & $V D \mathcal{f}-1$ & VDf-2 & WIG-1 & WIG-2 \\
\hline 1 & - & - & - & + & 1 & 1 \\
2 & + & + & + & + & 1 & 2 \\
4 & - & $+1-$ & + & + & 2 & 1 \\
10 & + & + & - & - & 2 & 2 \\
11 & + & + & - & + & 1 & 3 \\
12 & - & - & + & - & $3 / 4$ & 3 \\
17 & + & - & - & + & 2 & 1 \\
18 & - & - & + & + & 1 & $2 / 3$ \\
19 & + & - & - & - & 3 & 2 \\
20 & + & - & + & + & 1 & 1
\end{tabular}

HP-1, 2 = Helicobacter pylori positive or negative in the first or second gastric biopsy; $\mathrm{VDJ}=\mathbf{B}$ cell clonal analysis WIG = Wotherspoon-Isaacson grading score for lymphoid infiltration of the gastric tissue.

RELATIONSHIP BETWEEN CLONAL B CELL

EXPANSION AND MALT

As far as the relationship between VDJ clonal expansion and lymphoid follicles in the stomach is concerned, only $14 \%$ of those with such follicles (one of seven) were VDJ positive, compared with $57 \%$ (eight of 14) of those lacking lymphoid follicles (grade 1). The $\chi_{c}^{2}$ value of 3.49 is barely significant for a mutual exclusion (table 4 ).

\section{CLONAL EXPANSION AND INFECTION}

We found that $H$ pylori infection explained only $44.4 \%$ of all VDJ clonalities at the first assessment. After the second biopsy, the number of $H$ pylori positive samples had decreased, yet the number of VDJ positive samples was increased (table 3). $H$ pylori infection in these patients seems to be resistant to the common treatment strategy for its eradication (Sorrentino et al, manuscript in preparation): only three of six samples were cleared of the bacilli. Interestingly, one patient who was VDJ negative at the first assessment and did not receive treatment had become VDJ positive at the second biopsy and, conversely, one initially VDJ positive patient had become VDJ negative at the second sample.

Only one sample of nine with clonal expansion had a Wotherspoon-Isaacson grading score grade $3 / 4$; the others were grade 1 or 2 .

\section{MALT IN CONTROL SUBJECTS}

Organised lymphoid tissue was detected in $21.5 \%$ of the samples, and $H$ pylori infection in $63 \%$. H pylori infection was found in $82 \%$ of the gastric specimens with lymphoid follicles.

While the majority of VDJ clonal expansion in SS was observed in those without lymphoid follicles, in the controls the opposite was seen, as reported elsewhere. ${ }^{18}$

Table 4 VDf clonality, Helicobacter pylori (HP), Epstein-Barr virus (EBV), and human herpes virus 6 (HHV-6) infections related to lymphoid follicles in patients with Sjögren's syndrome

\begin{tabular}{lllll}
\hline Patients & $V D f(+)$ & $H P(+)$ & $E B V(+)$ & $H H V-6(+)$ \\
\hline $\begin{array}{c}\text { LF positive } \\
(\mathrm{n}=7)\end{array}$ & $1(14 \%)^{\star}$ & $5(71 \%)$ & $2(29 \%)$ & $2(29 \%)$ \\
$\begin{array}{c}\text { LF negative } \\
(\mathrm{n}=14)\end{array}$ & $8(57 \%)$ & $10(71 \%)$ & 0 & $1(7 \%)$ \\
\hline LF = Lymphoid follicles ${ }^{\star}{ }^{\star} \mathrm{C}^{2}=3.49: 0-05 \% \mathrm{p}<0$ &
\end{tabular}




\section{Discussion}

Gastritis of SS was previously labelled as an atrophic gastritis with or without intestinal metaplasia. ${ }^{19} 20$ In previous studies, gastric biopsy specimens have shown mononuclear cell infiltrates of the lamina propria, and the prevalent cells were typed as T lymphocytes of the CD4 phenotype; ${ }^{21}$ our findings confirm these data.

The immunophenotypic analysis of the lymphoid cells infiltrating the mucosa resembles very closely that found in minor salivary glands. In this study, we observed gastric lymphoid follicles in a slightly greater percentage of SS patients compared with the control group. Lymphoepithelial lesions with evidence of B lymphocytes infiltrating the epithelium, consistent with the criteria for 'suspicious lymphoid infiltrate' according to Wotherspoon et al, ${ }^{14}$ were found in $14.3 \%$ of the SS samples.

There is a growing consensus concerning the role of $H$ pylori in the development of lymphoid follicles in the general population; however we found no such relationship in SS.

The first important finding of this study was that abnormal accumulation of MALT may occur in the stomach even in the absence of $H$ pylori infection in Sjögren's syndrome. Lymphoid follicles were present in only $33 \%$ of the SS gastric specimens with evidence of $H$ pylori infection. This point deserves to be stressed, as an almost uniform relationship between $H$ pylori and follicles has been reported in the literature. In the study by Wotherspoon et al, ${ }^{14} \mathrm{H}$ pylori was found in $92 \%$ of those with gastric MALT lymphomas that were diagnosed when B cells infiltrated the epithelium to form lymphoepithelial lesions. Genta $e t a l^{22}$ reported that all subjects with $H$ pylori had follicles, thus raising the possibility that lymphoid follicles are the normal response of the gastric mucosa to the $H$ pylori infection. Among their 62 infected patients, eight subjects had lymphoid tissue that virtually obliterated the lamina propria, pushing pits and glands to the side and occasionally creating lymphoepithelial lesions, and the authors labelled these patients as 'hyper-reactive'-those more likely to develop gastric lymphomas.

Another interesting finding of our study was the presence of infectious agents other than $H$ pylori in the gastric tissue, namely EBV or HHV-6, considered to be a possible cause of persistent lymphoid proliferation even in the labial salivary glands. ${ }^{23}$ It is also well known that EBV may be found in gastric carcinoma with marked lymphoid stroma. ${ }^{24}$ To our knowledge this is the first time that EBV or HHV- 6 has been detected in the stomach of patients with SS. It was possible to exclude a carry over effect in at least two patients who were negative in mononuclear blood cells, therefore a true infection of the tissue was a possibility. In our series an association between EBV and $H$ pylori was observed in one patient, while HHV-6 was observed in two samples positive for $H$ pylori. As no clear association was found between lymphoid follicles and any of the infectious agents we tested, we may hypothesise that perhaps other yet unknown infectious agents are harboured in the stomach, as has been described for the salivary glands, ${ }^{25}$ or that environmental factors ${ }^{26}$ or autoantigens $\mathrm{s}^{27}$ are involved.

The third main finding of our study was that a clonal expansion, as detected by a sensitive PCR technique, is a fairly common event in SS gastric lesions: it was demonstrated in $42.8 \%$ of cases. Most importantly, B cell clonality may appear in the absence of follicles. This is clearly a point of major interest because it emphasises the part played by the environment. Only $55.5 \%$ (five of nine) of the cases may be explained by a persistent antigenic stimuli as shown here through histochemical and genotypic analysis of infectious agents. This finding may support those of Pablos et $a l^{28}$ who demonstrated clonally expanded lymphocytes in all minor salivary glands of their 14 patients, yet only one patient developed a plasma cell tumour that differed from the expanded clone in the labial salivary glands. The possibility that B cell clonality may not always be linked to an identifiable infectious agent in SS is reinforced by the results of the second assessment which showed first, that the clonal B cell expansion could occur without any $H$ pylori infection; second, that even after eradication of the infection the clonality was still present, and third, and perhaps more important, that the clonal expansion may appear and vanish over time. Again, this point strengthens the role of the tissue microenvironment in the genesis of MALT and of clonality in these patients.

In summary, we have demonstrated the presence of MALT in the stomach of patients with SS. Even in the most recent review, ${ }^{29}$ the issue of gastric MALT and of the possible roles of infectious or non-infectious agents in the development of clonal B expansion was neither considered nor discussed. Our data show that a clonal rearrangement may be demonstrated in gastric tissues in which evidence of an infectious agent is not always present. As clonality seems to appear and disappear in the tissue in a fashion apparently independent of infectious antigenic stimuli or treatments, it is difficult to define its prognostic implications. It might represent the first step towards a neoplastic lymphoproliferative disease, which obviously would require the occurrence of additional genetic events, or it might represent the final step of an antigen driven (infectious antigen or autoantigen) lymphoid proliferation. ${ }^{27} 30$

It is well recognised that patients with SS are at high risk for lymphoma, ${ }^{31} 32$ yet gastric lymphoma is not frequent in these patients. Our data strongly support this background literature by providing evidence that $H$ pylori infection is not more frequent among patients with SS than in controls, and that clonal expansion and $H$ pylori infection ${ }^{33}$ are not always associated events in this disease. Considering that gastric lymphoma is rare, while clonal B cell expansion appears frequently in gastric tissues of patients with SS, we are led to conclude that these gastric clonalities are 'benign' if pathological features of suspect gastric lymphoma are absent and a lymphoproliferative disorder is not detected elsewhere. 
Nevertheless, caution in the use of immunosuppressive drugs is clearly advisable, as any oncogenic risk might be detrimental to these patients.

Study supported by grant No 93.04402.CT04 to GFF; grant AIDS 1995 Project, Ministero Sanita' Roma to DDL; and grants from Associazione Italiana Ricerca sul cancro, Ministero della Sanita', Ricerca Finalizzata 1994 and CNR special project ACRO No 95.00504, PF39 to MB.

We wish to thank Professor H M Moutsopoulos (Department of Pathophysiology, Medical School, National University of Athens) for his helpful suggestions.

1 Isaacson P G, Spencer J. Malignant lymphoma of mucosa associated lymphoid tissue. Histopathology 1987; 11: 445-62.

2 Bayerdorffer E, Neubauer A, Rudolph B, et al. Regression of primary gastric lymphoma of mucosa associated lymphoid tissue type after cure of Helicobacter pylor infection. Lancet 1995; 345: 1591-4.

3 Saito I, Servenius B, Comptom T, Fox R T. Detection of Epstein-Barr virus DNA by polymerase chain reactions in blood and tissue biopsies from patients with Sjögren's syndrome. $\mathcal{F}$ Exp Med 1989; 169: 2191-8.

4 Talal $N$, Dauphinee $M J$, Dang $H$, Alexander S S, Hart D J, Garry R F. Detection of serum antibodies to retroviral proteins in primary Siögren's syndrome (autoimmune exocrinopathy). Arthritis Rheum 1990; 33: 77-81.

5 Fox R I, Saito I, Chan E K. Viral genomes in lymphomas of patients with Sjögren's syndrome. I Autoimmunity

6 Hatz R A, Brooks W P, Kramling H J, Enders G. Stomach immunology and Helicobacter pylori infection. Curr Opin Gastroenterol 1992; 8: 993-1001.

7 Isaacson P G. Gastric lymphoma and Helicobacter pylori. NEngl f Med 1994; 330: 1310-1.

8 Moutsopoulos H M. Sjögren's syndrome: autoimmune epithelitis. Clin Immunol Immunopathol 1994; 72: 162-5.

9 Costantopoulos S H, Tsianos E V, Moutsopoulos H M. Pulmonary and gastrointestinal manifestations of Sjögren's syndrome. Rheum Dis Clin N Am 1992; 18: Sjögren's

10 Diss T C, Peng H, Wotherspoon A C, Pan L, Speight P M, Isaacson $\mathrm{P}$ G. A single neoplastic clone in sequential biopsy specimens from a patient with primary gastric mucosa associated lymphoid tissue lymphoma and Sjögren's syndrome. N Engl f Med 1993; 329: 172-5.

11 De Vita S, Ferraccioli G F, De Re V, et al. Polymerase chain reaction detects $B$ cell clonalities in patients with Sjögren's syndrome and suspected malignant lymphoma. f Rheumatol 1994; 21: 1497-501.

12 Vitali C, Bombardieri S, Moutsopoulos H M, et al. Preliminary criteria for the classification of Sjögren's syndrome. Results of a prospective concerted action supported by the European Community. Arthritis Rheum 1993; 36: 340-7.

13 Chisholm D M, Mason D K. Labial salivary gland biopsy in Sjögren's disease. F Clin Pathol 1968; 21: 656-60.

14 Wotherspoon A C, Ortiz-Hidalgo C, Falzon M R, Isaacson P G. Helicobacter pylori-associated gastritis and primary B cell gastric lymphoma. Lancet 1991; 338: 1175-6.

15 Di Luca D, Dolcetti R, Mirandola P, et al. Human herpes virus 6: a survey of presence and variant distribution in normal peripheral lymphocytes and lymphoproliferative disorders. F Infect Dis 1994; 170: 211-5.

16 Boiocchi M, De Re V, Dolcetti R, Carbone A, Scarpa A, Menestrina F. Association of Epstein-Barr virus genome with mixed cellularity and cellular phase nodular sclerosis with mixed cellularity and cellular phase nodular sclerosis

17 Aubin J, Collandre H, Candotti D, et al. Several groups among human herpes virus 6 strains can be distinguished by Southern blotting and polymerase chain reaction. $f$ by Southern blotting and polym

18 Ferraccioli G F, Sorrentino D, De Vita S. B cell clonality in gastric mucosa of patients with Sjögren's syndrome: relationship with Helicobacter pylori, EBV and human herpes virus 6 (HHV-6) infections. Arthritis Rheum 1994; 24 (suppl): abs 1484

19 Pokornyi G, Karacsony G, Lonovics J, Hudak J. Types of atrophic gastritis in patients with primary Sjögren's syndrome. Ann Rheum Dis 1991; 50: 97-100.

20 Maury C P J, Tornroth T, Teppo A M. Atrophic gastritis in Sjögren's syndrome. Arthritis Rheum 1985; 28: in Sjögren.

21 Kilpi A, Bergroth V, Konttinen Y T, Maury C P J, Reitamo S, Wegelius $O$. Lymphocyte infiltration of the gastric mucosa in Sjögren's syndrome. An immunoperoxidase study using monoclonal antibodies in the avidin-biotin peroxidase method. Arthritis Rheum 1983; 26: 1196-200.

22 Genta R M, Wentzell Hammer H, Graham D Y. Gastric lymphoid follicles in Helicobacter pylori infection. Hum Pathol 1993; 24: 577-83.

23 De Clerk L S, Bougeois N, Krueger G R F, Stevens W J. Human herpes virus 6 in Sjogren's syndrome. In: Ablashi D V, Krueger G R F, Salahuddin S Z, eds. Human Herpes Virus 6. Amsterdam: Elsevier Science Publishers Herpes Virus 6. Am

24 Watanabe H, Enjoji M, Imai T. Gastric carcinoma with lymphoid stroma. Cancer 1976; 38: 232-43.

25 Garry R F, Fermin C D, Hart D J, Alexander S S, Donehoover L A, Luo-Zhang H. Detection of a human intracisternal A type retroviral particle antigenically related to HIV. Science 1990; 250: 1127-9.

26 Fagioli F, Rigolin G, Cuneo A, et al. Primary gastric lymphoma: distribution and clinical relevance of different epidemiological factors. Haematologica 1994; 79: 213-7.

27 Yannopoulos D I, Roncin S, Lamour A, Pennec Y L, Moutsopoulos H M, Yoinou P. Conjunctival epithelial cells from patients with Sjögren's syndrome inapcells from patients with Sjogren's syndrome inappropriately express major histocompatibility complex molecules, La(SSB) antigen and

28 Pablos J L, Carreira P E, Morillas L, Montalvo G, Ballestin C, Gomez-Reino J J. Clonally expanded lymphocytes in the minor salivary glands of Sjögren's syndrome patients without lymphoproliferative disease. Arthritis Rheum 1994; 37: 1441-4.

29 Sheikh S H, Shaw-Stiffel T A. The gastrointestinal manifestations of Sjögren's syndrome. Am $\mathcal{F}$ Gastroenterol 1995; 90: 9-14.

30 Parsonnet J, Hansen S, Rodriguez L, et al. Helicobacter pylori infection and gastric lymphoma. $N$ Engl $7 \mathrm{Med}$ 1994; 330: 1267-71

31 Kassan S S, Thomas T L, Moutsopoulos H M, et al. Increased risk of lymphoma in sicca syndrome. Ann Int Med 1978; 89: 888-92.

32 Pisa E K, Pisa P, Kang H I, Fox R I. High frequency of $t(14 ; 18)$ translocation in salivary gland lymphomas from Sjögren's syndrome patients. F Exp Med 1991; 174: 1245-50.

33 Stolte $M$, Eidt S. Healing gastric MALT lymphomas by eradicating $\mathrm{H}$ pylori? Lancet 1993 ; 342: 568-9. 